\title{
Digital education: cultural aspects of communication in the modern educational environment
}

\author{
Inna Zilberova*, Marina Alyaeva, Fotina Shuraeva, and Konstantin Petrov \\ Don State University, 344000, Rostov-on-Don, Russia
}

\begin{abstract}
The article presents an analysis of modern approaches to the concepts of "information and educational environment" and" digital educational environment", in which modern students - future bachelorsdevelop competencies in the field of intercultural communication. Special attention is paid to the consideration of the features of professional training, as well as the requirements for future specialists. The problems of modern digital education closely follow from the problems of verbal interaction of communicants in the educational environment. The considered issues of updating the needs for an educational product cannot be separated from the realization of the possibilities of didactic and methodological support for digital education, which is realized in the communicative interaction of a student and a teacher. The authors conducted a number of experimental studies in the field of studying the needs of students in educational services and the opportunities for teachers to effectively realize their educational potential. The authors offer recommendations for improving educational technologies in the context of digitalization, improving the technical and communicative literacy of teachers, conducting trainings and trainings aimed at increasing the stress tolerance of teachers, providing them with comfortable working conditions in remote mode, modernizing the system of technical regulation in the process of providing educational activities, conducting explanatory work with students, motivating them to contact work in remote access, improving the culture of group and interpersonal communication
\end{abstract}

\section{Introduction}

The increase of digitization in the economy predetermines the enlargement the volume of virtual communication. In turn, this presupposes the formation of new forms of social and verbal human behavior, the revision of values and categories that determine interaction in society. Communication flows penetrating into all spheres of human activity make virtual interaction massive and significant. On the one hand, the emerging culture requires reflection within the framework of culture-philosophical analysis - testing technologies for their cultural consistency and value in the aspect of analyzing the fundamental problems of transforming the human being and society, because it is formed not one - common to all

\footnotetext{
* Corresponding author: lncs@springer.com
} 
reality, but multitude. On the other hand, it calls for the renewal of the culture-philosophical knowledge itself and the ways of its translation into the scientific and educational environment, taking into account the possibilities and requirements of new technological realities.

\section{Materials and methods}

When increasing the activity of the interaction between people, in terms of improving the technical means of communication formed a new type of culture - the culture of virtual communication. Characterizing this phenomenon, we can distinguish its basic properties: non-linear mode of existence of the communicating subject, virtualization of public relations, the increasing role of social institutions that form the space of virtual communications, etc.

This study examines the problems of the correlation of contemporary culture and communication in the digital educational environment [1].

The cultural and economic basis of the civilization development has recently become the subject of hard discussions. Does culture represent the same intangible value as other objects that have an immaterial value, and what is the place of culture in the information world? The abundance of educational programs, blogs, courses, distance education among universities and private resources raise questions "what to teach and how to teach" in a completely different plane. In the modern world, we can talk about the existence of an entire economy of virtual educational services, including technical profile. There is a necessity for effective interaction between the student and the teacher in the context of remote education. In our study, we can defined necessity as the need for something, without which the natural life of a person and his formation as a member of society are impossible. This definition helps us to understand the objective essence of the necessity, its objective expression.

However, any necessity also has a subjective expression, determined by the impact of needs on the subject (personality, collective, society and its organizations), on biosocial, intellectual-cognitive, aesthetic-emotional, moral and other spheres of his life and which finds expression in the form of a natural reaction subject - a feeling of lack or unwanted excess of something [2].

Consequently, if we ignore instinctive reactions that cannot be influenced, then the essence of subjective expression consists in awareness, understanding, etc., of a given necessity. This, as a rule, finds an active reflection of the personal position, expressed in speech behavior and reactions to certain material or moral stimulus.

Personal priorities may be in conflict with the public need. Public need corresponds to the objective and subjective sides of the need. If a real, natural or public demand for something exists, but is not realized by the subjects, then we cannot talk about the need. Subjective expression of necessity, that is, a certain idea of the need for something or even a feeling of lack (undesirable excess) of something, can exist relatively independently of those primary objective conditions that contributed to the emergence of the need. If, however, the subjective expression of needs not related to its objective character and if the first does not take into account the restrictions imposed on needs by the reproduction process, then we cannot talk about social needs, although they can declare themselves as such really and sometimes very intensely [3-5].

The mismatch between the needs of the system and its environment is overcome based on:

- changing the environment by increasing the production of material products and services, changing the mode of production and the way of consumption in this case by creating a digital educational product. At the same time, it is assumed that need is an 
existing ideal image of the future, desired consumption, it is a generalized internal driving force of consumption, in our case - the desire of learning to expand one's own capabilities;

- adjusting needs in the course of their social verification in a given system of public relations, that is, a qualitative transition to the level of virtual reality, the objectification of spatial and personal properties.

Public need as a category has a complex character; its various sides are expressed in objective and subjective dimensions and find themselves in constant internal contradiction [6].

If the "external", objective, expression of the need has been determined, and the "internal" has not yet taken shape, then it is premature or ineffective to convince the subject of the need for this necessity. Therefore, first, it is necessary to create conditions in the field of the formation of subjective needs.

If the subjective, "internal", state has already been formed, and the objective, "external", has not yet matured, then this can lead to a loss of internal incentives to satisfy this need, and then either there will be a reorientation to other needs, or even an unreasonable dissatisfaction will appear. In education, this is fixed in the form of the impossibility of realizing the acquired knowledge or skills on the one hand, and on the other hand, in the formation of a cognitive barrier that prevents a person from learning from the student's side [7-9].

What explains the subjectivity in the approach to educational needs? In our opinion, the reason for subjectivity lies in the confusion of the two sides of the issue. On the one hand, all anthropological needs must be taken into account. On the other hand, the objective nature of needs lies in the fact that social-production relations and the economic basis, which determine the conditions for the formation and satisfaction of needs, objectively determine them [10-12].

In contemporary digital education, there are signs of the formation of the following needs in the educational system "teacher-student":

a) the universality of the individual needs, including the factors of choice and freedom;

b) the full development of all creative abilities of a person [13];

c) the all-round development of individuals ceases to be a means, but becomes a primary goal, becomes a measure of the economic and social development of society;

d) free self-affirmation of the person as a member of society [14-15];

e) free self-realization of personality in professional and other spheres.

The criterion of rationality (irrationality) of educational needs is:

a) its qualitative aspect (primary definition), that is, does this need reflect the objective necessary professional, cultural and social conditions of a person and trends in their development;

b) its quantitative aspect (secondary definition), i.e., to what extent this need corresponds (or does not correspond) to the objective need for education, mastering competencies, skills, etc.

\section{Results and discussion}

The problems of modern digital education closely follow from the problems of verbal interaction of communicants in the educational environment. The considered issues of actualizing the needs for an educational product cannot be separated from the implementation of the possibilities of didactic and methodological support of digital education, which is implemented in the communicative interaction of a student and a teacher. 
Today, the main attention and time of the teacher's educational work is concentrated on providing students with data, familiarizing them with information, transferring knowledge and forming their understanding. As the study shows, there is a definite relationship between the presence of a perlocutionary effect (the presence of feedback) and the effectiveness of distance learning (Fig.1).

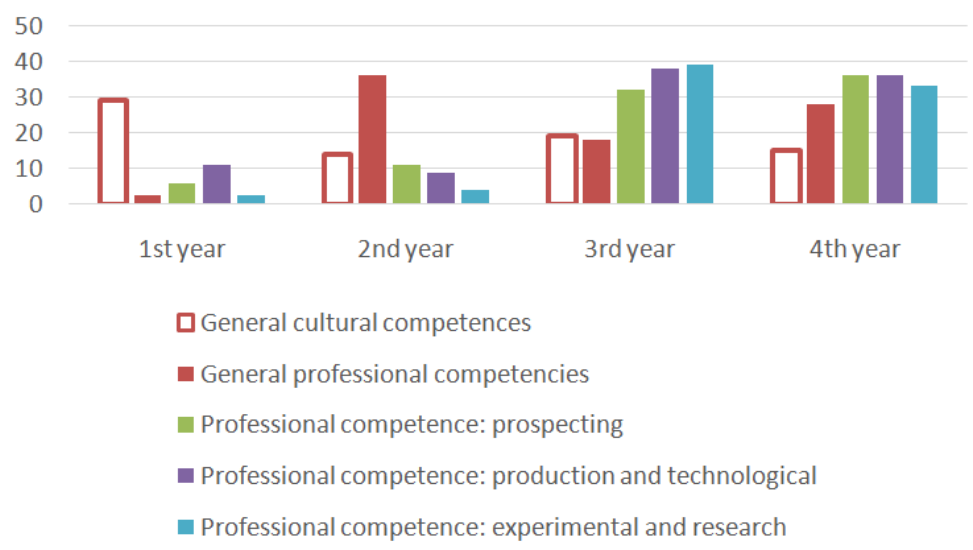

Fig. 1. The mastering competencies on bachelor's programs in the direction 08.03.01 Construction in $\%$ from $100 \%$ competence based on the results of control and cut works during the period of distance learning (Development of the authors)

The diagram of the development of competencies shows that the result in the studied period is quite low, and not a single competence is mastered by $50 \%$ of the possible maximum. At the same time, the distribution of mastering among students shows other dependencies:

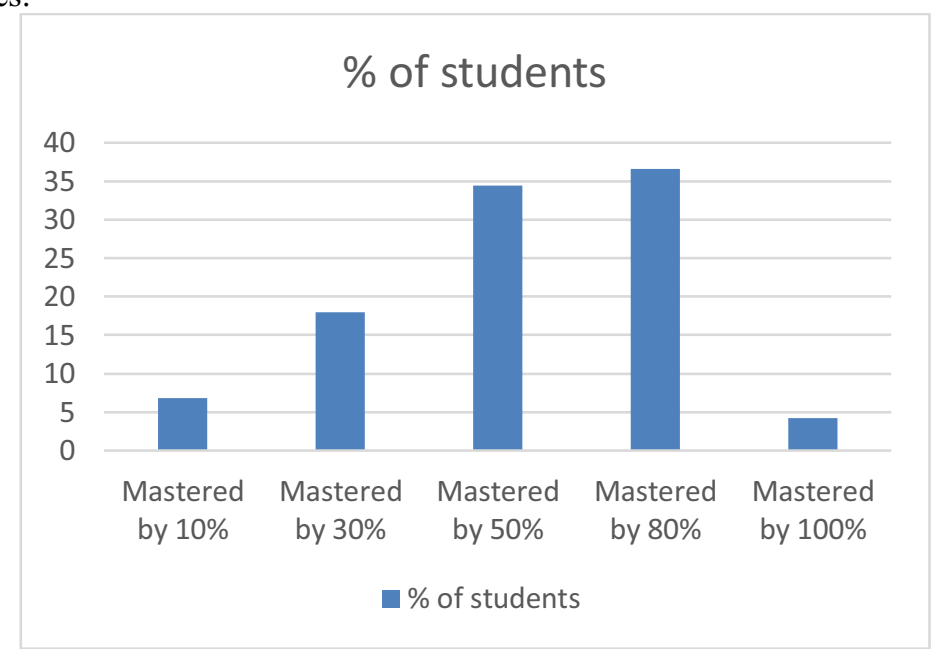

Fig. 2. Mastering the total number of students on all competencies for bachelor's programs in the direction 08.03.01 Construction in $\%$ of $100 \%$ competence (Development of the authors)

Thus, the number of learners who have mastered the program is $75.2 \%$ of the total number of students who took part in the study. This shows us that the students received some knowledge in the professional field, but this knowledge requires further improvement for full professional implementation.

These data can be compared with research data on the development of competencies in the study of disciplines in a full-time classroom work format. 


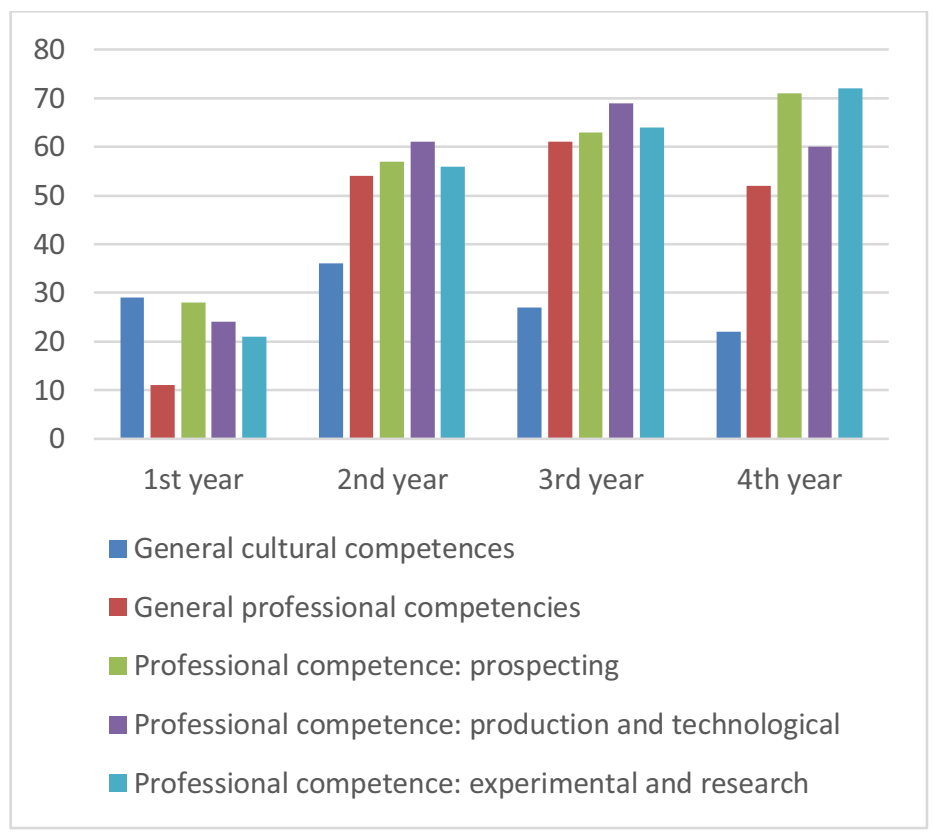

Fig. 3. The mastering competencies on bachelor's programs in the direction 08.03.01 (Development of the authors)

Construction in $\%$ from $100 \%$ competence based on the results of control and cut works during the period of full-time classroom training

As the research data show, in full-time classroom training, the percentage of mastering competencies is above average, except for the first year of study. The low percentage of education shows only the development of common cultural competence.

An analysis of students` necessities, carried out through a questionnaire survey, showed the following differentiation of educational requests:

Table 1. Determining the priorities of students' needs in the development of areas of the educational program

\begin{tabular}{|l|l|}
\hline \multicolumn{1}{|c|}{ Name of the mastered area } & Percentage specified priority \\
\hline $\begin{array}{l}\text { 1. Engineering surveys, design of buildings } \\
\text { and constructions; }\end{array}$ & $\begin{array}{l}1 \text { priority }-74 \% \\
2 \text { priority }-12 \% \\
3 \text { priority }-14 \%\end{array}$ \\
\hline $\begin{array}{l}\text { 2. Engineering support and equipment of } \\
\text { construction sites and urban areas; }\end{array}$ & $\begin{array}{l}1 \text { priority }-65 \% \\
2 \text { priority }-17 \% \\
3 \text { priority- } 18 \%\end{array}$ \\
\hline 3. Application of machinery, equipment and & 1 priority $-54 \%$ \\
technologies for building works; & 2 priority $-42 \%$ \\
& 3 priority $-4 \%$ \\
\hline 4. Business and production management in & 1 priority $-76 \%$ \\
the building sector; & 2 priority $-23 \%$ \\
& 3 priority $-1 \%$ \\
\hline 5. Technical and environmental safety in the & 1 priority $-17 \%$ \\
building sector & 2 priority $-36 \%$ \\
& 3 priority $-47 \%$ \\
\hline
\end{tabular}




\begin{tabular}{|l|l|}
\hline 6. Historical sciences & 1 priority $-0 \%$ \\
& 2 priority $-7 \%$ \\
3 priority $-93 \%$ \\
\hline 7. Philosophical sciences & 1 priority $-0 \%$ \\
& 2 priority $-4 \%$ \\
& 3 priority $-96 \%$ \\
\hline 8. Foreign language & 1 priority $-22 \%$ \\
& 2 priority $-8 \%$ \\
& 3 priority $-70 \%$ \\
\hline
\end{tabular}

As the analysis of the results shows, students prioritize purely practical skills in accordance with their personal ideas about the essence of the industry.

Comparing these data with the results of teachers' feedback about the effectiveness of speech communication (Fig. 4), we can draw conclusions about the patterns of the results of mastering the competencies of students, implemented as feedback.

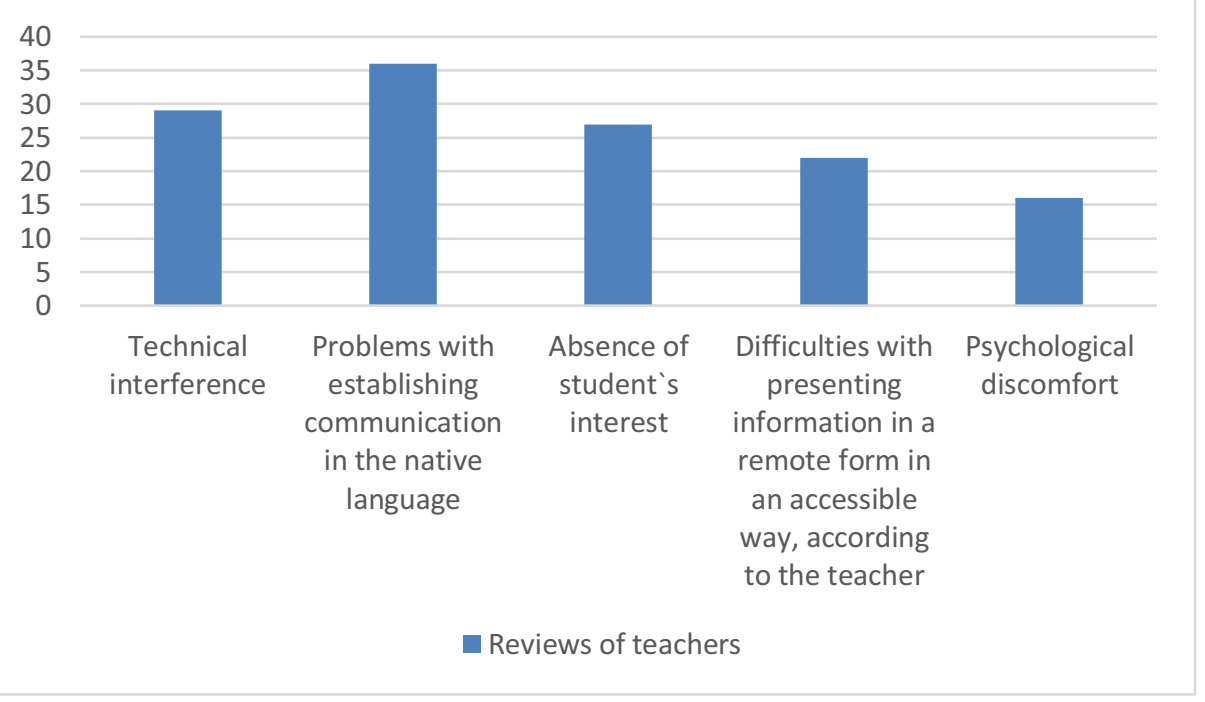

Fig. 4. Results of a questionnaire survey on the problems of teacher communication in a distancelearning environment (Development of the authors)

The main problems, according to teachers, are difficult communication with foreign students. The lack of interest among students, difficulty in presenting information in a distance mode is in second place in terms of reviews. Among the teachers' comments to the questionnaire can be found the following comments: "It's hard to tell when you are here and they are at home"; "Many sit imposingly lounging, some just sleep during the lecture".

These remarks indicate a low degree of teacher-student contact when the teacher is performing duties and the student is serving voluntary service. In this case, the educational process does not affect in any way on the acquisition of the necessary knowledge and the satisfaction of educational needs.

\section{Conclusion}

Summing up, as recommendations for improving educational technologies in the context of digitalization, the authors suggest: 
1. Improving the technical and communication literacy of teachers. Conducting coaching and training courses designed to increase the resistance to stress of teachers, to provide them with comfortable working conditions in a distance mode.

2. Modernization of the technical regulation system in the process of providing educational activities.

3. Carrying out explanatory work with students, motivating them to contact work in conditions of remote access, increasing the culture of group and interpersonal communication.

\section{References}

1. E.V. Gryazeva, Social partnership as one of the conditions for quality training of specialists, Modern trends in the management of industrial innovative organizations: collection of scientific articles, region. Scientific and practical conf. with internat. participation (Alatyr, September 28-29, 2017), Cheboksary, Chuvash Publishing House un-ta, 2017.

2. V.G. Kvachev, I.M. Divilkovskiy, Social resources of modernization, State management: The Russian Federation in the modern world, Proceedings of the KHGG International Conference. (2015) 105-109.

3. S.B. Kotlyarov, E.A. Chicherov, Law and education 7, 117-122 (2017).

4. A.N. Makarevich, VestnikNovSU 74, 53-56 (2013).

5. M.A. Panfilov, S.B. Kotlyarov, E.A. Chicherov, Organizational forms of interaction between government and business at the regional level, Professional of the Year 2016: collection of articles of the International Scientific and Practical Competition, Under the general editorship of G.Y. Gulyaev, Penza, ICNS "Science and Education" (2016) 80-84.

6. O.A. Podolsky, V.A. Pogozhina, Humanitarian studies 1, 96-103 (2016).

7. N.V. Potekhina, Yu.I. Shulinina, Theory and practice of social development 3, 2016. Information on https:/cyberieninka.ru/article/n/ vzaimosvyaz-tehnologicheskihukladov-i-obrazovaniya-kak-chasti-chelovecheskogo-kapitala (accessed 10.09.2018).

8. N.Yu. Nevraeva, A.M. Kabanov, N.Kh. Savel'eva, N.I. Sorokina, Review of pedagogical research 2 (3), 105-111 (2020).

9. C.M. Woodward, A History of the St. Louis Bridge (St. Louis, G. I. Jones, 1881).

10. F. van Eemeren, P. Houtlisse, Argumentation and Rationality, The Though: Argumentation 6, 7-22 (2006).

11. T. Volosovets, I, Kirillov, and A. Buyanov, Procedia - Social and Behavioral Sciences 237, 1299-1303 (2017). doi: 10.1016/j.sbspro.2017. 02.213.

12. O.V. Kliuchnikova, O.A. Pobegaylov, Procedia Engineering 150, 2168-2172 (2016). http://www.sciencedirect.com/science/journal/18777058. 10.1016/j.proeng.2016.07.259

13. E. Shirina, G. Myasischev, The degrading value-based orientations of the linguistic personality in the infomedia of the contemporary internet public communication, Proceedings of the International Conference on the Theory and Practice of Personality Formation in Modern Society (ICTPPFMS 2018). Electronic edition. Ser. "Advances in Social Science, Education and Humanities Research" 4-7 (2018).

14. O. Gaibaryan G. Myasischev, Proceedings of the International Conference on the Theory and Practice of Personality Formation in Modern Society (ICTPPFMS 2018). 
Electronic edition. Ser. "Advances in Social Science, Education and Humanities Research" 14-18 (2018).

15. K. Gudkova, Cognitive-Pragmatic Analysis of Argumentation in the Analytical Paper Article (on the British press matter), PhD Thesis, St. Petersburg (2009).

16. M.Yu. Seyranyan, Conflict discourse: sociolinguistic and pragmalinguistic aspects, monograph, Moscow, 2012. 